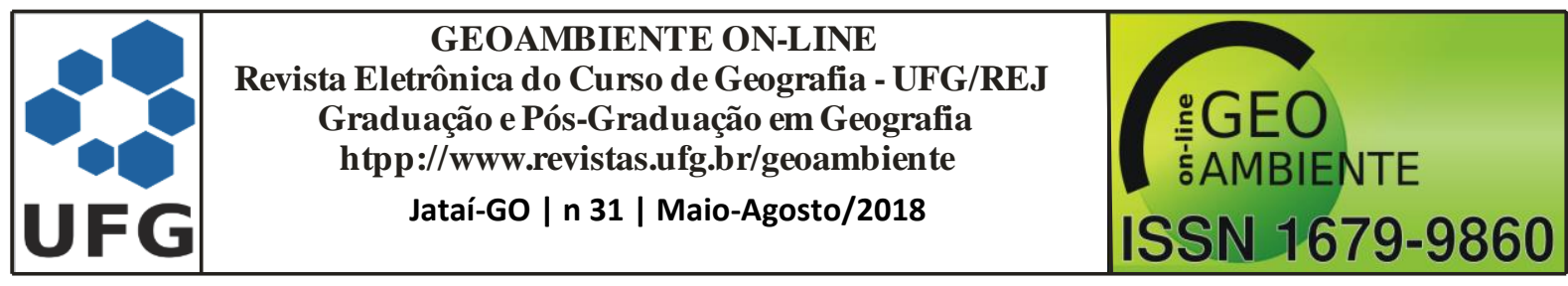

\title{
ANÁLISE ESPACIAL DAS ÁREAS DE INUNDAÇÕES EM MONTES CLAROS/MG, ASSINALADAS PELO PLANO MUNICIPAL DE
} SANEAMENTO BÁSICO DE 2015

Francielle Gonçalves Silva ${ }^{\mathbf{1}}$, Marcos Esdras Leite ${ }^{\mathbf{2}}$, Maykon Fredson Freitas Ferreira ${ }^{\mathbf{3}}$ (1 - Universidade Federal de Goiás - UFG, Doutoranda em Geografia, francielle.geounimontes@gmail.com, 2 - Universidade Estadual de Monte Claro - Unimontes, Docente, Departamento de Geociências, marcosesdrasleite@gmail.com, 3 - Universidade Estadual de Monte Claro - Unimontes, Mestre em Geografia, maykonfredson@gmail.com)

Resumo: Nos métodos de análise de vulnerabilidade, a Cartografia de Risco assume papel fundamental. Os sistemas de informações geográficas - SIGs são imprescindíveis, pois possibilitam as mais diferentes tarefas de planejamento, permitindo o trabalho com grande volume de dados em diferentes escalas. Esta análise permite relacionar diferentes informações em um determinado contexto espacial, e traçar relações, em um curto espaço de tempo, a exemplo do entendimento dos processos decorrentes da dinâmica hidrológica e da formação socioespacial das áreas suscetíveis a inundações. O objetivo deste estudo é compreender o espaço do ponto de vista da ocupação urbana nas áreas mais suscetíveis a inundações, conforme o modelo elaborado por Leite e Rocha (2016), especificamente nos pontos mapeados pelo Plano Municipal de Saneamento Básico de Montes Claros/MG - PMSBMC (2015). Para isso, foram utilizados os seguintes dados: áreas de alagamento no perímetro urbano da cidade, delimitado pelo estudo técnico (PMSBMC 2015); modelo de suscetibilidade a inundação no perímetro urbano de Montes Claros, elaborado por Leite e Rocha (2016); e por último, intercalou-se esses dados aos setores censitários do IBGE 2010 (número de residências e renda domiciliar). Os resultados obtidos permitiram identificar a população mais suscetível às inundações e as áreas de maior vulnerabilidade social.

Palavras-chave: SIG. Suscetibilidade a Inundação. Vulnerabilidade.

\section{SPACE ANALYSIS OF THE FLOOD AREAS IN MONTES CLAROS/MG INDICATED BY THE MUNICIPAL SANITATION PLAN OF 2015}

\footnotetext{
Artigo recebido para publicação em 26 de Junho de 2017

Artigo aprovado para publicação em 15 de Maio de 2018
} 


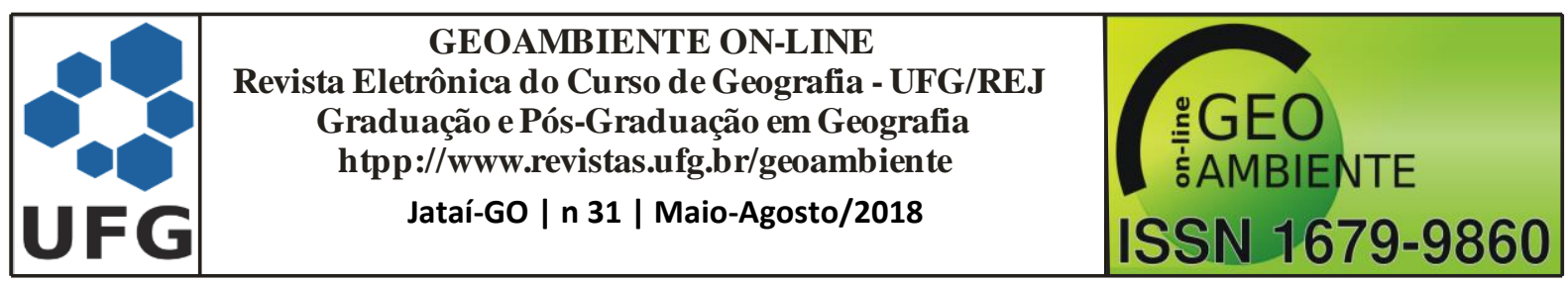

Abstract: In the methods of vulnerability analysis, Risk Mapping assumes a fundamental role. Geographic information systems - GIS are essential, since the yallow the most different planning tasks, allowing the work with great volume of data in different scales. This analysis makes it possible to relate different information in a given spatial context, and to draw relation ships, in a short period of time, as an example of the understanding of processes arising from the hydrological dynamics and socio-spatial formation of áreas susceptible to flooding. The objective of this study is to understand the space from the point of view of urbano ccupation in the areas most susceptible to flooding, according to the model elaborated by Leite and Rocha (2016), specifically in the points mapped by the Municipal Plan of Basic Sanitationof Montes Claros/MG - PMSBMC (2015). For this, the following data were used: areas of flooding in th eurban perimeter of the city, delimited by the technical study (PMSBMC 2015); model of flood susceptibility in the urban perimeter of Montes Claros, prepared by Leite and Rocha (2016); and finally, these data were intercalated to the censustracts of IBGE 2010 (number of residences and househ old in come). The resultsobtainedallowedtoidentifythepopulationmostsusceptibletofloodsandareasofgreater social vulnerability.

Keywords: GIS. Susceptibility a Flood. Vulnerability.

\section{ANÁLISIS ESPACIAL DE LAS ÁREAS DE INUNDACIÓN EN MONTES CLAROS / MG FIRMADAS POR EL PLAN MUNICIPAL DE SANEAMIENTO BÁSICO DE} 2015

Resumen: En los métodos de análisis de vulnerabilidad, la Cartografía de Riesgo desempeña un papel fundamental. Los sistemas de información geográfica - SIG son imprescindibles, porque posibilitan las más diferentes tareas de planificación, permitiendo el trabajo con gran volumen de datos en diferentes escalas. Este análisis permite relacionar diferentes informaciones en un determinado contexto espacial, y trazar relaciones en un corto espacio de tiempo, a ejemplo del entendimiento de los procesos derivados de la dinámica hidrológica y de la formación socioespacial de las áreas susceptibles a inundaciones. El objetivo de este estudio es comprender el espacio desde el punto de vista de la ocupación urbana en las áreas más susceptibles a la inundación, según el modelo elaborado por Leite \& Rocha (2016), específicamente en los puntos mapeados por el Plan Municipal de Saneamiento Basico de Montes Claros / MG - PMSBMC (2015). Para ello, se utilizaron los siguientes datos: áreas de 


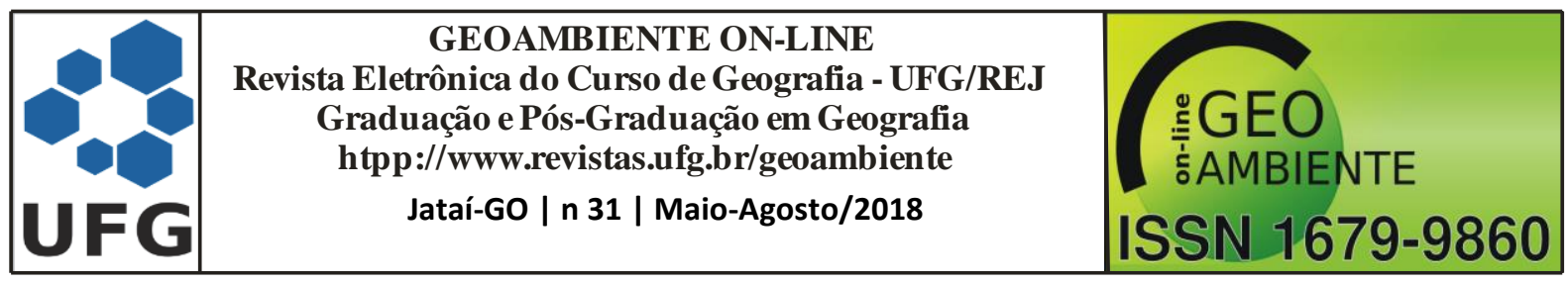

inundación en el perímetro urbano de la ciudad, delimitado por el estudio técnico (PMSBMC 2015); modelo de susceptibilidad a inundación en el perímetro urbano de Montes Claros, elaborado por Leite \& Rocha (2016); y por último, se intercalaron esos datos a los sectores censales del IBGE 2010 (número de residencias e ingresos domiciliarios). Los resultados obtenidos permitieron identificar la población más susceptible a las inundaciones y las áreas de mayor vulnerabilidad social.

Palabras clave: SIG. Suscetibilidade a inundación. Vulnerabilidad.

\section{Introdução}

Um dos principais problemas ambientais nas cidades brasileiras é a ocorrência de inundação, aos quais, dadas as características da urbanização em países subdesenvolvidos, adquirem o caráter de risco hidrológico ou hidrometeorológico. As inundações e enchentes são eventos naturais que ocorrem com periodicidade nos cursos d'água, frequentemente resultante de chuvas fortes e rápidas ou chuvas de longa duração. As suas consequências podem ser agravadas quando a população ocupa áreas suscetíveis e com alto perigo de recorrência.

Neste contexto, as geotecnologias são uma das muitas alternativas para o mapeamento do potencial de ocorrência de eventos perigosos relacionados com o ambiente e a interferência antrópica. Munidos de informações cartográficas é possível, por parte dos gestores públicos, planejar e executar ações de ordenamento do território ou mesmo a gestão de impactos, com isso, espera-se evitar a perda material e, em casos mais graves, de vidas humanas.

Montes Claros, no contexto de cidade média, apresenta um significativo processo de urbanização que tem gerado cada vez mais problemas de ordenamento territorial. Neste contexto, as inundações figuram como processos singulares nessa dinâmica. O planejamento inadequado, aliado a ação do mercado imobiliário que conduz a ocupação do solo urbano, dentre outros fatores, tem contribuído para o quadro atual.

Portanto, este artigo se apoiou no Plano Municipal de Saneamento Básico de Montes Claros/MG - PMSBMC que foi publicado em 2015, no qual consta um estudo técnico que delimitou os pontos de alagamento no perímetro urbano da cidade. Também, no trabalho de Leite e Rocha (2016), que traçou um modelo para delimitar as áreas suscetíveis a inundação no perímetro urbano de Montes Claros. E, por último, nos setores censitário do IBGE 2010, elaborados para o perímetro urbano da cidade. 


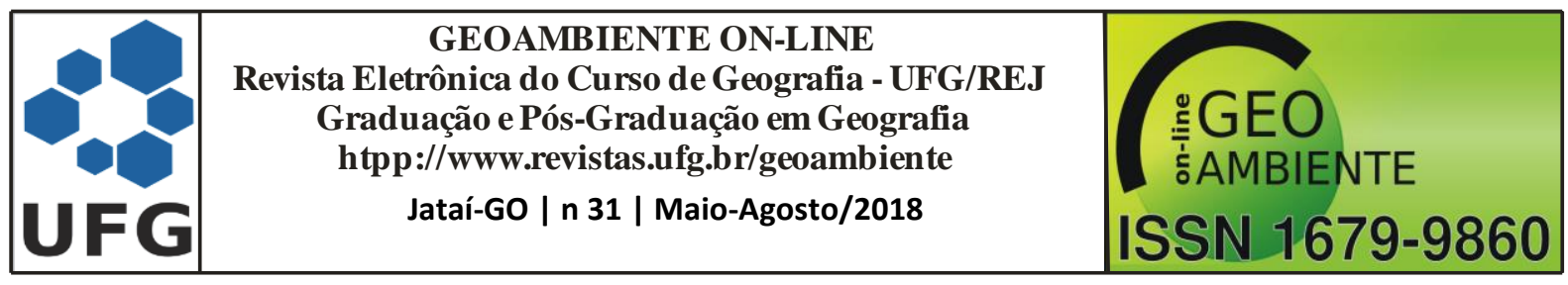

Assim, o objetivo principal deste artigo foi compreender o espaço do ponto de vista de ocupação urbana nas áreas mais suscetíveis a inundação, conforme o modelo elaborado por Leite e Rocha (2016), especificamente nos pontos mapeados pelo PMSBMC (2015).

Notadamente, buscou-se considerar a área de interesse em termos quantitativos, levando em consideração o número de edificações construídas e área correspondente a renda domiciliar do censo IBGE 2010. Através disso, foi possível responder as perguntas sobre o processo de ocupação dessas áreas, tais como: qual área de interesse da pesquisa possui maior ou menor densidade residencial? Qual área possui maior ou menor número de residências? E qual a extensão das áreas de interesse correspondente a renda domiciliar? Diante das respostas dessas perguntas, procura-se compreender a espacialidade urbana nas áreas mais suscetíveis à inundação, apontados pelo PMSBMC.

Os Sistemas de Informação Geográfica - SIGs foi a aplicação básica que permitiu a manipulação de uma base cartográfica georreferenciada, passível de ser manipulada por várias entidades e instituições que gerem o território. Aqui, neste artigo, se recorrerá a este tipo de ferramenta de trabalho para a análise da espacialidade urbana do território, mais precisamente a análise das áreas sob maior suscetibilidade à inundação na cidade de Montes Claros, Norte de Minas Gerais.

Espera-se que este estudo possa subsidiar algumas ações governamentais no tocante ao ordenamento territorial nas áreas suscetíveis a inundação que serão analisadas, já que, será compreendido alguns aspectos populacionais em termos de área ocupada, mesmo que exista algumas discrepâncias apresentadas no trabalho realizado pelo PMSBMC.

\section{Referencial teórico}

A análise dos fenômenos espaciais, com todas as suas especificidades, é preponderante para a compreensão de diversos temas que cercam a sociedade, seja ela econômica, social, ambiental, saúde e outros. Isso é explicado por Câmara et al. (2001), e ainda ressaltam, que essa análise foi facilitada pela disponibilidade de Sistemas de Informação Geográfica (SIGs), que, agora possuem baixos custos e interfaces amigáveis. Buzai e Baxendale (2006) elencam a importância da Geografia como ciência que está no centro deste processo, e, claramente, tem-se convertido na disciplina central dessa evolução.

Os Sistemas de Informações Geográficas (SIGs) são instrumentos poderosos e valiosos no tratamento de dados espaciais. Agregam um maior quantitativo de dados e 


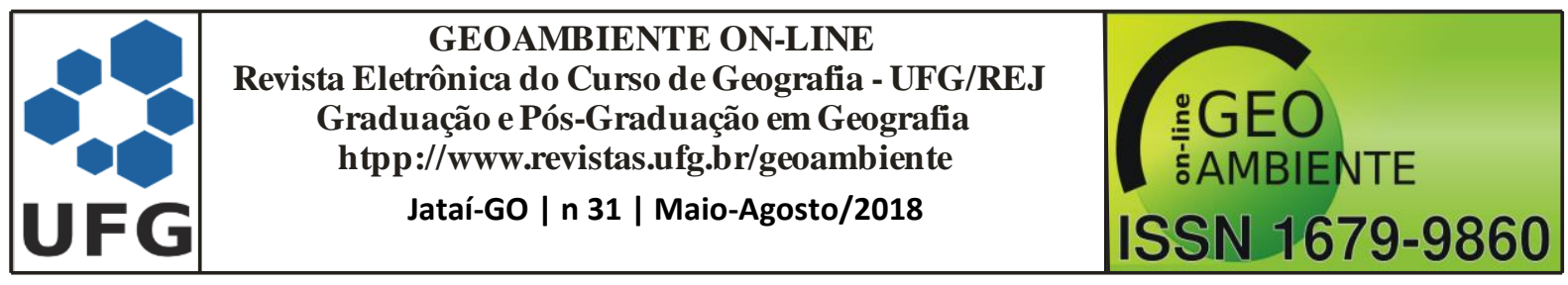

transforma-os em dados geográficos espacializados. Portanto, tem a visão espacial como enfoque, o que possibilita as tecnologias digitais dar maior atenção a organização espacial através da gestão e planejamento (BUZAI e BAXENDALE, 2006). A importância dos SIGs consiste, dentre outros, na sua capacidade em relacionar diferentes informações em um determinado contexto espacial e permite traçar relações em um curto espaço de tempo. Desta forma, os SIGs têm produzido uma revolução tecnológica e uma revolução intelectual.

Os SIGs constituem um valioso instrumento na modelação, cartografia e análise das diferentes características da população, favorecendo o conhecimento de situações ou fenômenos espacialmente distribuídos (CUNHA e RAMOS, 2013).

É importante frisar, também, que os SIGs permitem análises espaciais complexas, a partir do tratamento de dados geográficos e seus atributos, aos quais são posteriormente inseridos em bases de dados. A eficácia da ferramenta SIGs na análise, monitoramento e gestão de riscos pode ser atribuída a um dos principais problemas ambientais nas cidades brasileiras: a ocorrência de processos de inundações, aos quais, dadas as características da urbanização em países subdesenvolvidos, adquirem o caráter de risco hidrológico ou hidrometeorológico.

Neste sentido, a designação conceitual de alagamentos, inundações e enchentes perpassa pela compreensão dos processos de interferência antrópica no ciclo hidrológico, embora trata-se de fenômenos naturais. Assim, o uso e ocupação do solo no ambiente urbano provoca uma série de impactos sobre a dinâmica hidrológica, principalmente nas águas fluviais e pluviais.

As principais diferenças conceituais estão relacionadas ao comportamento do sistema de drenagem. Conforme Tominaga (2011), a elevação do nível d'água no canal decorrente do aumento da vazão, atingindo cota máxima sem extravasar, é um processo denominado de enchente. Enquanto a inundação corresponde ao transbordamento d'água do curso fluvial que atinge a planície de inundação ou área de várzea. Logo, o alagamento é o acumulo momentâneo da água em determinados locais por deficiência do sistema de drenagem.

É recorrente a utilização equivocada dos conceitos de enchentes e inundações, (especialmente pela mídia) tratados como se fossem sinônimos (NASCIMENTO, 2013). O que diferencia a enchente da inundação é o transbordamento da água, passando de um processo de enchente para inundação, consequentemente surge o risco a desastre natural (GOERL e KOBIYAMA, 2005). Desta forma, a inundação é processo natural do ciclo 


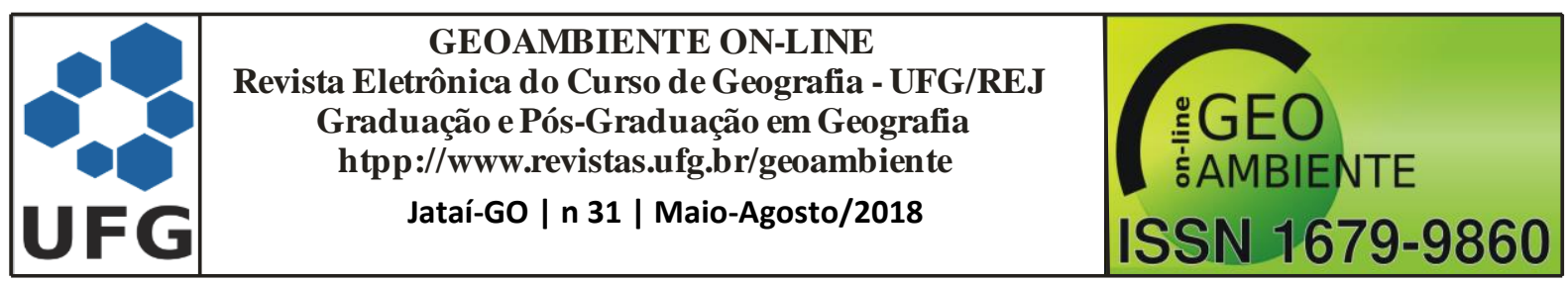

hidrológico, devido à variabilidade climática de curto, médio e longo prazo (TUCCI, 2005). Contudo, as suas consequências podem ser agravadas quando a população ocupa áreas suscetíveis e com alto perigo de recorrência.

A probabilidade e a ocorrência de inundação, enchente e alagamento são analisadas pela combinação entre os condicionantes naturais e antrópicos, salienta Amaral e Ribeiro (2009). Entre os condicionantes naturais destacam-se: a) formas do relevo; b) características da rede de drenagem da bacia hidrográfica; c) intensidade, quantidade, distribuição e frequência das chuvas; d) características do solo e o teor de umidade; e) presença ou ausência da cobertura vegetal.

Entre os condicionantes antrópicos citam-se: a) uso e ocupação irregular nas planícies e margens de cursos d'água; b) disposição irregular de lixo nas proximidades dos cursos d'água; c) alterações nas características da bacia hidrográfica e dos cursos d'água (vazão, retificação e canalização de cursos d'água, impermeabilização do solo, entre outras).

A inundação pode ocorrer por excesso de chuvas, por barreiras formadas no canal do rio, como os assoreamentos e lixos, comuns em áreas urbanas. Além disso, as inundações podem ocorrer através do comportamento natural do rio ou intensificado pelo processo de urbanização (impermeabilização e canalização dos rios). Dessa forma, Tucci e Bertoni (2003) definem dois tipos de inundações que podem ocorrer isoladamente ou de forma integrada em áreas urbanas. São as inundações de áreas ribeirinhas e as inundações devido à urbanização.

Para ele, as inundações ribeirinhas são processos naturais e ocorrem, em geral, em bacias de grande e médio porte, onde a declividade é baixa e a seção de escoamento é pequena. Para que ocorra esse tipo de inundação necessita-se de uma precipitação intensa que resulta em inundação nas áreas ribeirinhas. Os problemas gerados por esse tipo de inundação dependem do grau de ocupação da várzea pela população e da frequência com a qual as mesmas ocorrem.

As inundações inerentes à urbanização são processos influenciados por diversas atividades humanas realizadas nas áreas urbanas que sucedem geralmente em bacias pequenas. Esse tipo de inundação acontece à medida que a população impermeabiliza o solo, acelerando o escoamento, ou seja, aumenta a quantidade de água que passa nos condutos e canais. Essa elevada quantidade de água no sistema de drenagem causa inundações mais frequentes do que as que existiam quando a superfície era permeável e o escoamento se dava ao longo do terreno natural. 


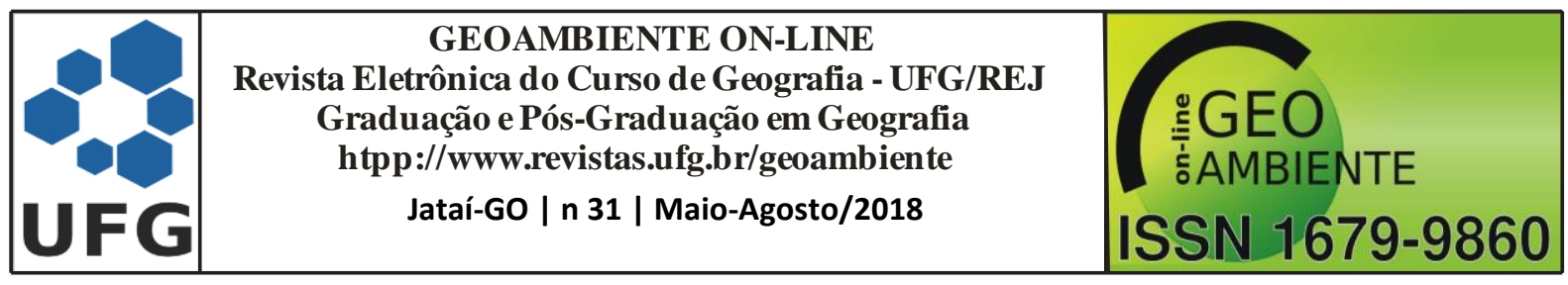

Essas ocorrências também acontecem diante da inexistência ou ineficiência do Plano Diretor. Isso é visto na maioria das áreas urbanas, a falta de restrições quanto ao loteamento de áreas suscetíveis a inundação. Tal situação pode ser evitada, de acordo com Tucci e Bertoni (2003), através do planejamento do uso do solo das várzeas.

No trato da cartografia de suscetibilidade, conforme afirma Cunha e Ramos (2013), na análise cartográfica do risco natural, quase sempre, se começa pela elaboração da cartografia de suscetibilidade, ou seja, a cartografia permite estabelecer a probabilidade espacial de ocorrência dos fenômenos perigosos.

Contudo, Cunha (2012), afirma que para alguns autores, os mapas de suscetibilidade, em grande parte, respondem também a probabilidade de ocorrência temporal, o que de certa forma, os transforma em mapas de periculosidade. Por outro lado, outros, tais como Garcia (2012), consideram necessário estabelecer mapas de probabilidade espacial de ocorrência para cenários conhecidos com diferentes períodos de retorno, ou seja, aos mapas de periculosidade.

No trato da cartografia de suscetibilidade, os métodos heurísticos ${ }^{1} /$ qualitativos, métodos quantitativos e métodos determinísticos são utilizados com sucesso na análise e espacialização de riscos à inundações e enchentes. A seleção dos métodos, são via de regra, por meio de fatores diversos tais como os tipos de risco em análise, a escala do estudo (metodologia a seguir) e a existência ou não de dados sobre as suas manifestações passiveis a aferição dos modelos (CUNHA e RAMOS, 2013).

No caso dos riscos hidrogeomorfológicos, não existem verdadeiras bases de dados com a distribuição, magnitude e consequências dos diferentes tipos de movimentos e processo de inundação e enchente de bacia hidrográfica, pelo que, quase sempre, é necessário fazer levantamentos exaustivos que passam por trabalho de campo, fotointerpretação e levantamento de notícias em órgãos de comunicação (fundamentalmente nos jornais nacionais e regionais), defesa civil e relatórios técnicos.

\section{Materiais e métodos}

A cidade de Montes Claros localiza-se na mesorregião do Norte de Minas Gerais inserida na Depressão Periférica do São Francisco, Bacia do Alto Médio São Francisco. A Bacia Hidrográfica do Rio Vieira é uma importante Bacia do município, seu afluente principal

\footnotetext{
${ }^{1}$ Heurística: é um conjunto de regras e métodos que conduzem à descoberta, à invenção e à resolução de problemas (BUENO, 2009).
} 


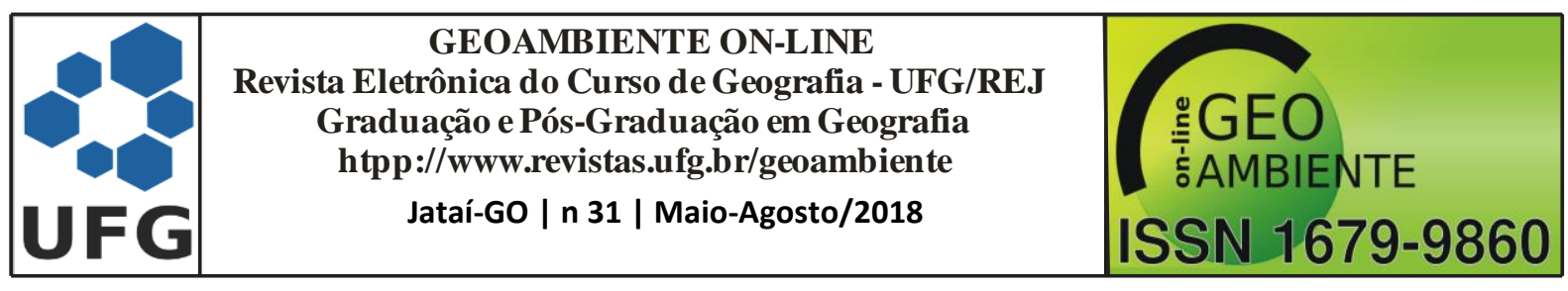

o Rio Vieira é um importante afluente da margem esquerda do Rio Verde Grande, que por sua vez é afluente da margem direita do Rio São Francisco. A Bacia Hidrográfica do Rio Vieira encontra-se totalmente inserida no município de Montes Claros (Figura 01). Por ter áreas ocupadas em espaço de drenagem urbana, é comum a ocupação em áreas suscetíveis a inundações.

Figura1 - Localização da área de estudo

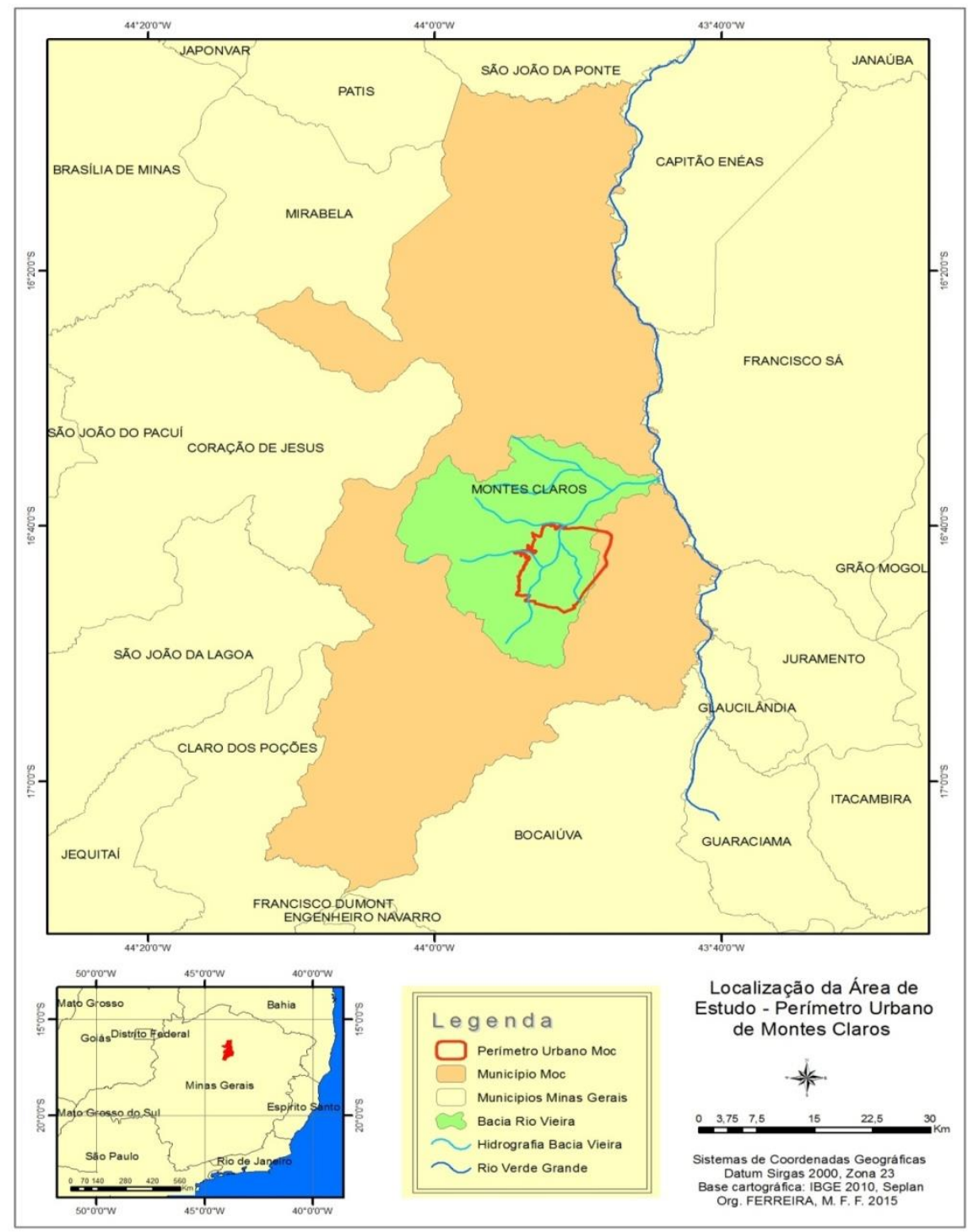

Fonte: IBGE, 2010; Secretária de planejamento Urbano (SEPLAN) - Montes Claros/MG. Org. FERREIRA, M. F. F. (2015). 


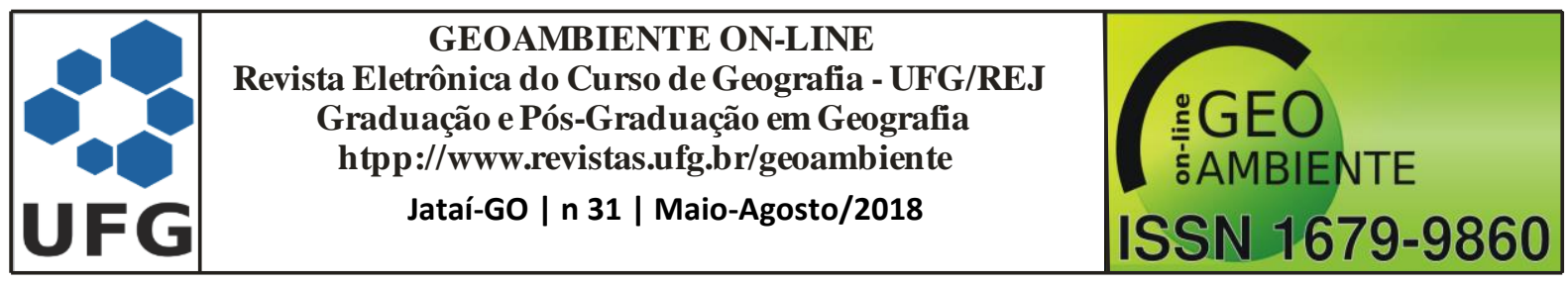

Montes Claros está inserida em uma área de 3.600,56 km² com uma população de 361.915 habitantes e densidade demográfica de 100,53 hab/ $\mathrm{km}^{2}$ (IBGE, 2010). Integra junto a outros municípios a área do Polígono da Seca, Região Mineira do Nordeste.

Administrativamente, o município é composto pela sede municipal, a cidade de Montes Claros e pelos Distritos de Ermidinha, Miralta, Nova Esperança, São Pedro das Garças, Santa Rosa de Lima, Vila Nova de Minas, Aparecida do Mundo Novo, Panorâmica, Canto do Engenho e várias comunidades rurais.

A hidrografia do município é dividida entres três bacias hidrográficas: bacia do Rio Pacuí, bacia do Rio São Lamberto e bacia do Rio Verde Grande, onde se encontra inserida a bacia do Córrego Vieira (LEITE, SANTOS e ALMEIDA, 2011). O Rio Vieira, afluente do Rio Verde Grande, é a principal rede hidrográfica totalmente de Montes Claros. Essa bacia se destaca por drenar a cidade de Montes Claros, logo, os problemas ambientais decorrentes das atividades urbanas atingem diretamente os rios da bacia.

A principal rede hidrográfica do município de Montes Claros, a bacia do Rio Viera tem sua nascente principal localizada na Fazenda Betânia, oito quilômetros a sudoeste da malha urbana, percorre no sentido norte do município e deságua a nordeste, no Rio Verde Grande, nas proximidades de uma região denominada Estação Ferroviária Canací.

Do ponto de vista físico-geográfico, Montes Claros caracteriza-se por apresentar elevadas temperaturas no decorrer do ano (média anual de $24^{\circ} \mathrm{C}$ ), verão quente e chuvoso, inverno seco e relativamente frio. O índice pluviométrico anual é de aproximadamente 1.200 mm. Predominam-se paisagens com áreas de transição entre os biomas cerrado e caatinga, mata seca caducifólia, e área de clima tropical semiúmido, com tendência a aridez (FRANÇA e SOARES, 2007).

A riqueza da composição litológica do município é predominantemente de relevo cárstico, solos de origem calcária. O relevo é constituído por uma porção elevada do terreno constituída por morros de calcário, pertencentes ao planalto residual do São Francisco; já a porção baixa e plana é denominada de depressão do São Francisco. O relevo caracteriza-se por feições onduladas (60\%), planas (30\%) e elevadas (10\%). Destacam-se as Serras (Geral, dos Montes Claros, dos Fonseca, de Baixo, Velha, Mão Porta, Cordilheira e Sapé), Chapadas (Lagoinha e Mocotó) e Grutas. (TOLMASQUIM, 2009).

Conforme Silva (2002), a formação geológica da região data da transgressão do mar de Bambuí, no pré-cambriano. Por ser uma região formada por transgressão marítima, o 


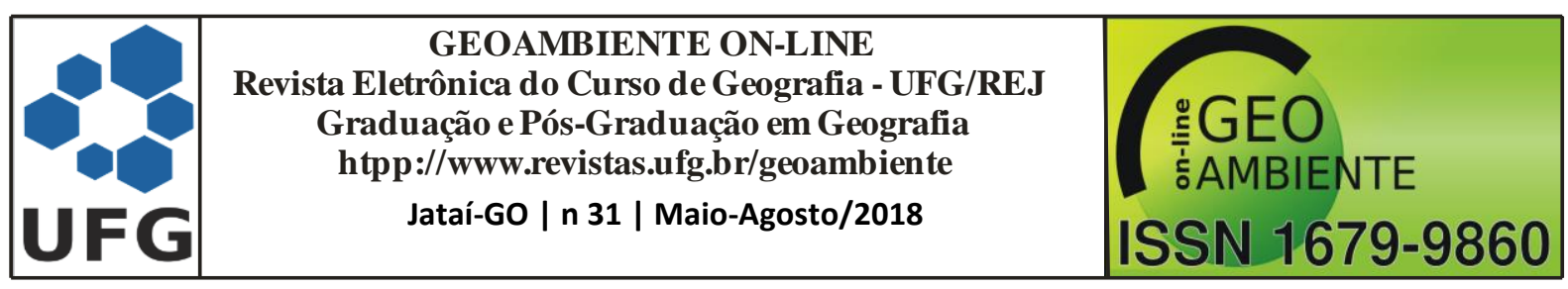

embasamento rochoso é composto principalmente por rochas calcárias, e é justamente este embasamento calcário, trabalhado e retrabalhado pelo clima e pela água, que definiu a geomorfologia do relevo cárstico da região.

Para a elaboração deste artigo e cumprimento dos objetivos, o trabalho foi estruturado em etapas, sendo a primeira etapa constituída da revisão bibliográfica, utilizando referências sobre aspectos conceituais dos SIGs e suas aplicações em análise espacial, principalmente em áreas urbanas. Além disso, buscou-se envolver algumas considerações sobre as inundações e referências sobre as características físicas da área analisada, tais como: clima, geologia, geomorfologia e hidrografia. Esta fundamentação teórica servirá de apoio às análises e interpretações dos resultados obtidos.

As próximas etapas (Figura 2) foram definidas para possibilitar a análise espacial e as características populacionais das áreas de interesse. Para isso, a metodologia tece análises quantitativas da área estudada, como extensão, quantidades de domicílios e renda. Estas análises foram baseadas no censo demográfico feito pelo IBGE 2010 e imagem de satélite de alta resolução espacial.

Figura 2- Organograma da metodologia

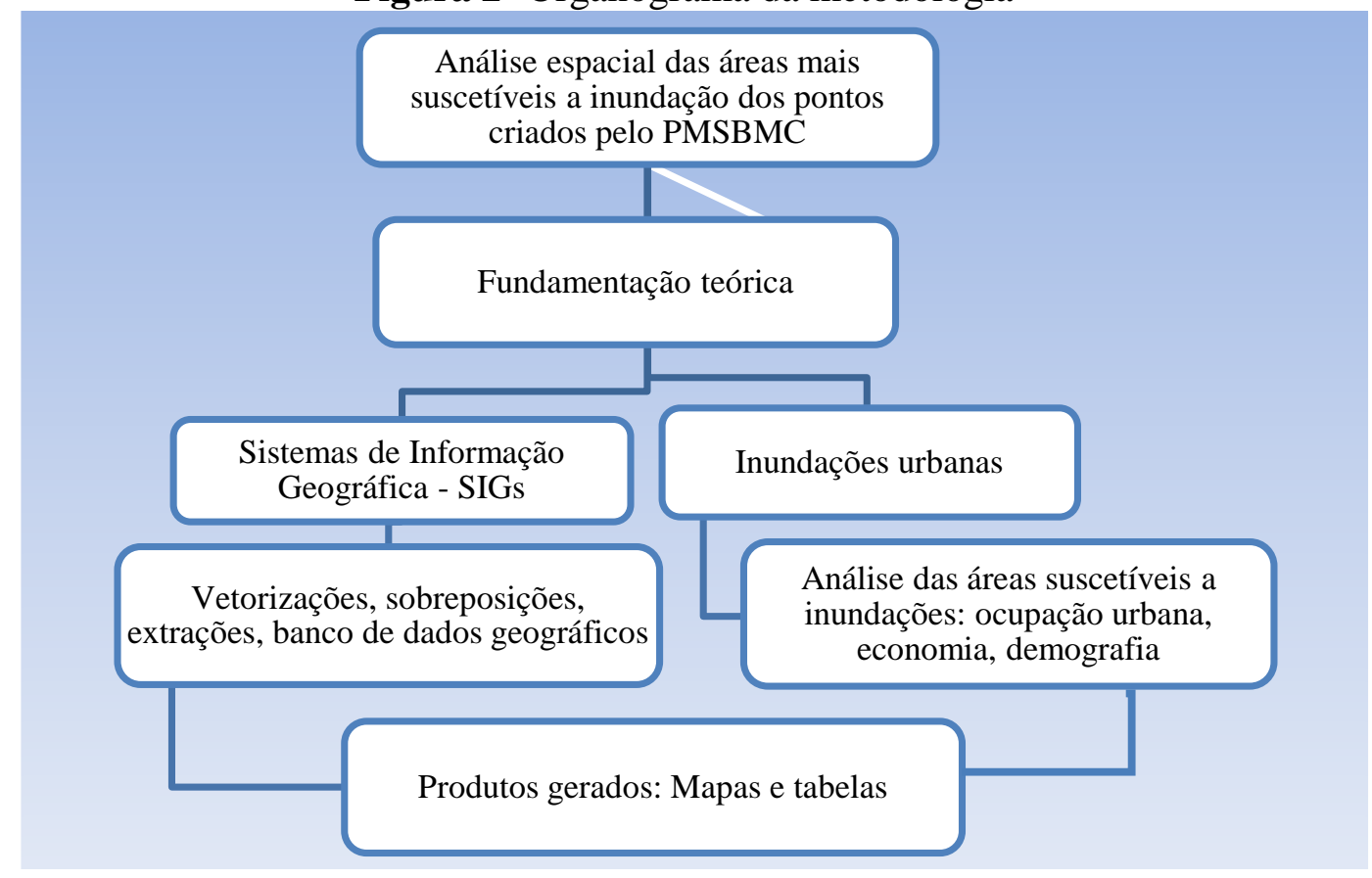

Organizado por SILVA, G. S., 2016. 


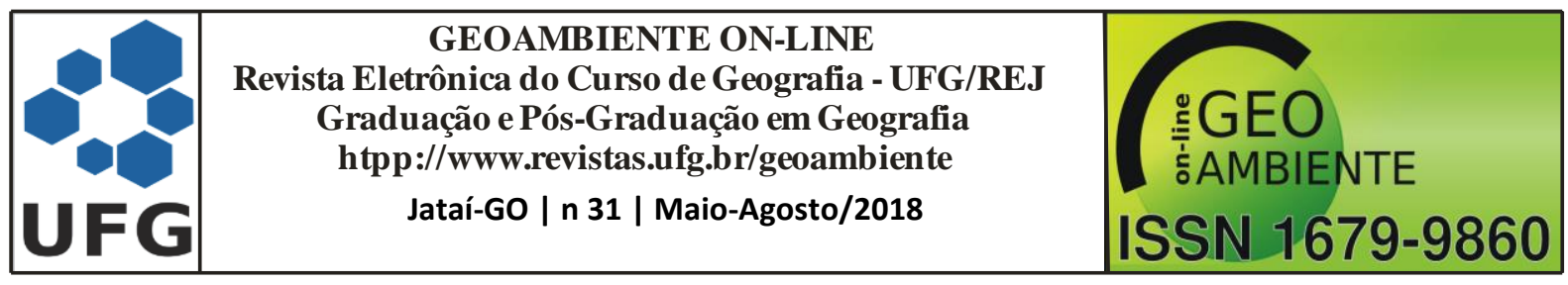

Esta pesquisa se desenvolveu principalmente em gabinete, no qual, lançou-se mão dos Sistemas de Informação Geográfica - SIGs para georreferenciar os mapas de áreas de alagamento e inundação do PMSBMC.Após isso, foram vetorizadas as 24 áreas apontadas pelo documento. Conforme, o PMSBMC estas áreas de alagamento foram identificadas a partir de levantamento em campo, logo após ter realizado um mapeamento com auxílio dos técnicos da Prefeitura Municipal de Montes Claros. Além disso, foi feita consulta a documentos que já trataram do assunto e análise de fotos e relatos sobre eventos que já ocorreram nos últimos anos.

Estes pontos de alagamento foram sobrepostos ao modelo de inundação elaborado por Leite e Rocha (2016)e extraído somente as áreas com "Alta e Altíssima" susceptibilidade de alagamento, chamada neste trabalho de área de interesse da pesquisa. Assim, foi possível observar nessas áreas a exposição da população às inundações, algo que servirá para um futuro trabalho de risco e vulnerabilidade dessa população aos agentes naturais.

Após, foram feitos campo para validação das áreas de interesse. Foram feitas anotações em caderneta e aquisição de fotografias digitais, visando compor o acervo da base de dados e a seleção de imagens ilustrativas das classes de suscetibilidade (modelo de LEITE e ROCHA, 2016)incidentes em cada caso para fins validação do plano de saneamento básico. Anotações diretas durante os trabalhos de campo mostraram-se, também, úteis aos procedimentos posteriores de revisão e consolidação do estudo, quando do retorno ao laboratório.

Dando continuidade,foi utilizada a imagem de satélite World View2, do ano de 2014,para vetorizar todas as residências que estão localizadas nas áreas de interesse, sendo possível saber a densidade residencial em cada ponto analisado. No próximo passo, as áreas de interesse foram sobrepostas aos setores censitários do IBGE (2010) e calculada em $\mathrm{m}^{2}$ as áreas correspondentes aos setores de renda domiciliar. Durante esse processo, criou-se um mapa de localização da área de estudo e mapas de espacialização das áreas de interesse, incluindo número de residências e renda domiciliar.

Finalmente, foram produzidas tabelas com dados quantitativos em termos de quantidade de domicílios e extensão de áreas correspondentes a renda domiciliar das áreas de interesse. Através desta metodologia será possível traçar um perfil da área de estudo quanto à exposição residencial às inundações e o poder econômico das áreas mais atingidas. 


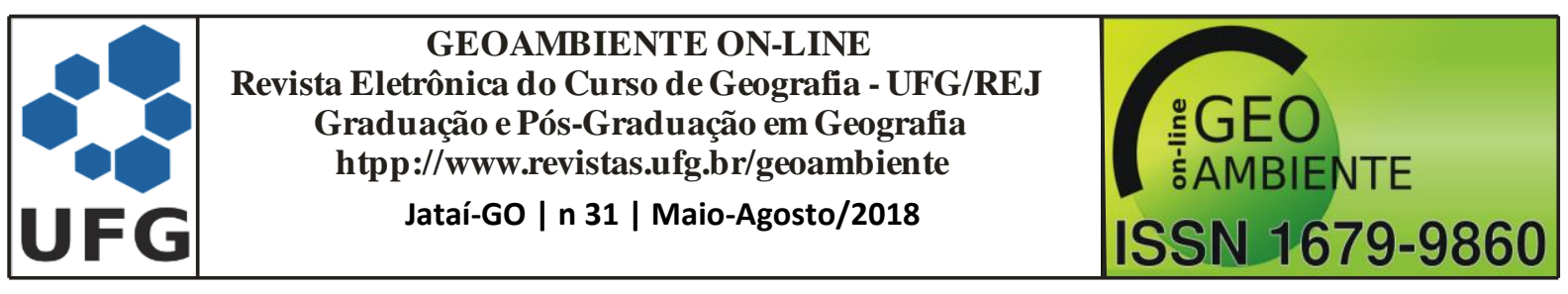

\section{Resultados e discussão}

A partir da metodologia aplicada neste artigo, no qual o SIGs foi imprescindível, obtiveram-se os dados quantitativos das áreas de maior suscetibilidade à inundação das áreas de alagamento do PMSBMC. Conforme exposto na figura 3, são vinte e quatro áreas de alagamento apontados no PMSBMC que estão sobrepostos ao modelo de áreas suscetíveis a inundação. A chamada área de interesse da pesquisa inclui somente as áreas de alta e altíssima suscetibilidade que estão localizadas nas áreas de alagamento do PMSBMC, como mostra a figura 3.

Figura 3 - Áreas de alagamento do PMSBMC sobrepostas ao modelo de inundação 


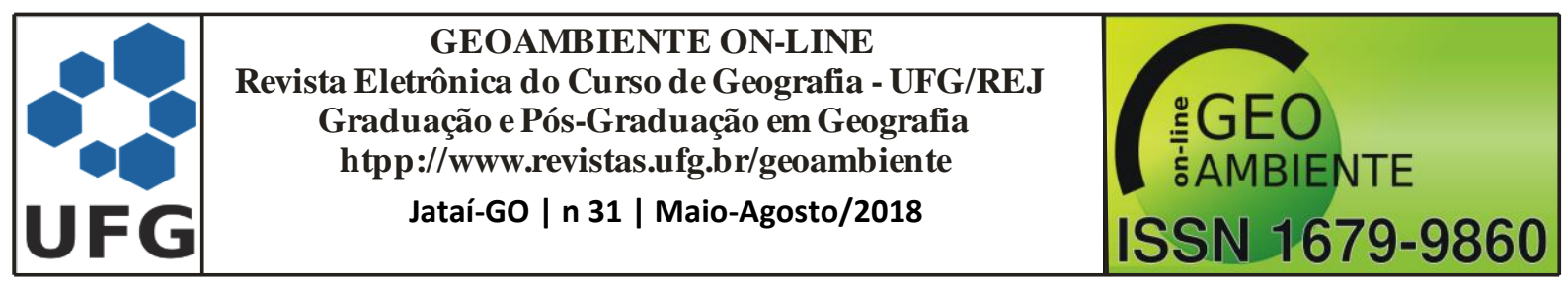

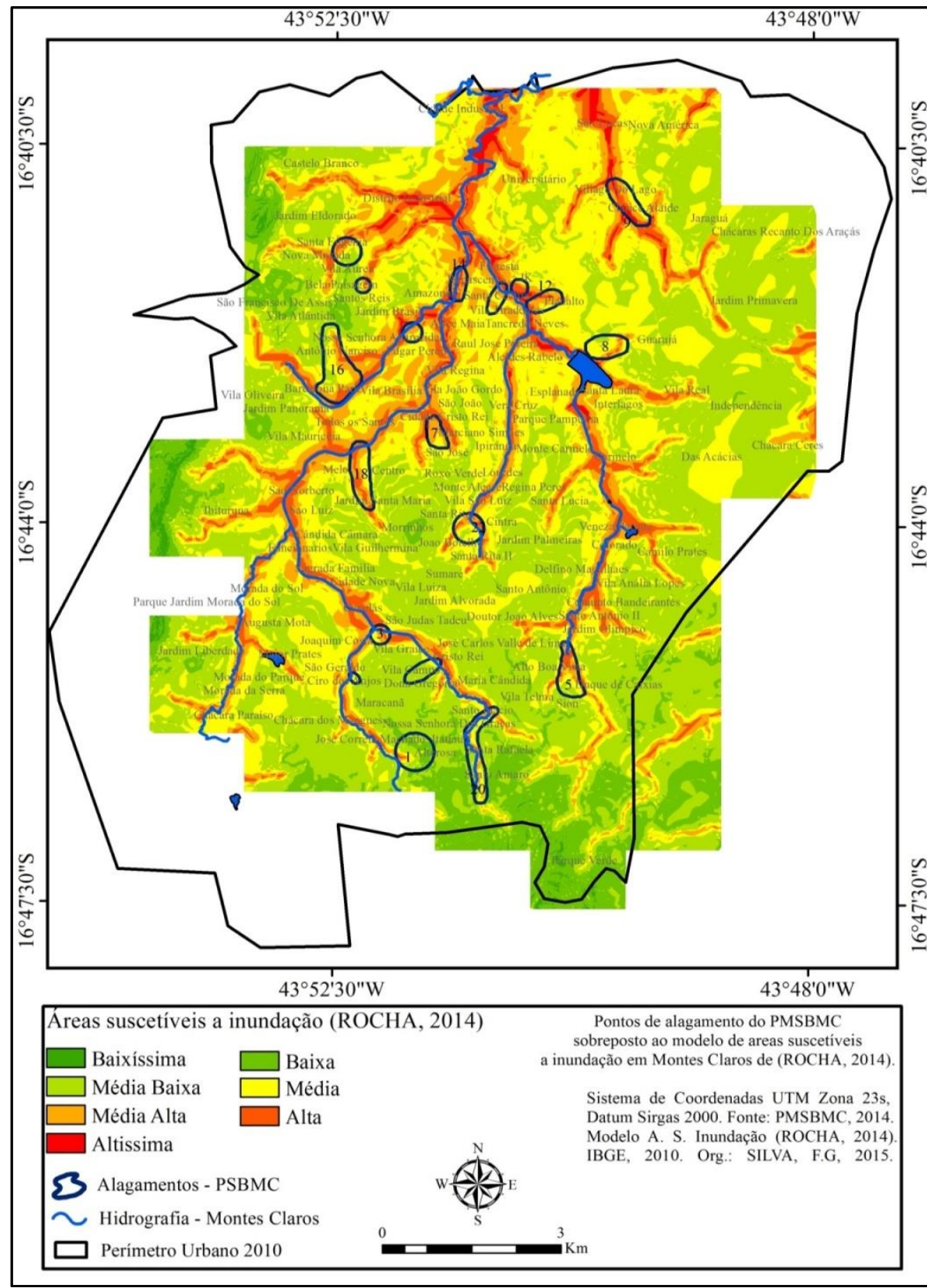

Fonte: IBGE, 2010; PMSBMC, 2014; ROCHA, 2014. Secretária de planejamento Urbano (SEPLAN) - Montes Claros/MG. Org. SILVA, F. G. (2015).

Ao analisar os dados da Tabela 1, percebe-se que se somadas às áreas de interesse da pesquisa, o valor é de $679.874 \mathrm{~m}^{2}$ o que corresponde a $16,2 \%$ da área total dos pontos estabelecidos do PMSBMC. Dentre as áreas com alta e altíssima suscetibilidade a inundação (área de interesse), a que possui maior extensão está dentro do ponto 18, com $89.569 \mathrm{~m}^{2}$, correspondendo a 13,1 \% da área total. Já a que possui menor extensão está dentro do ponto 2 


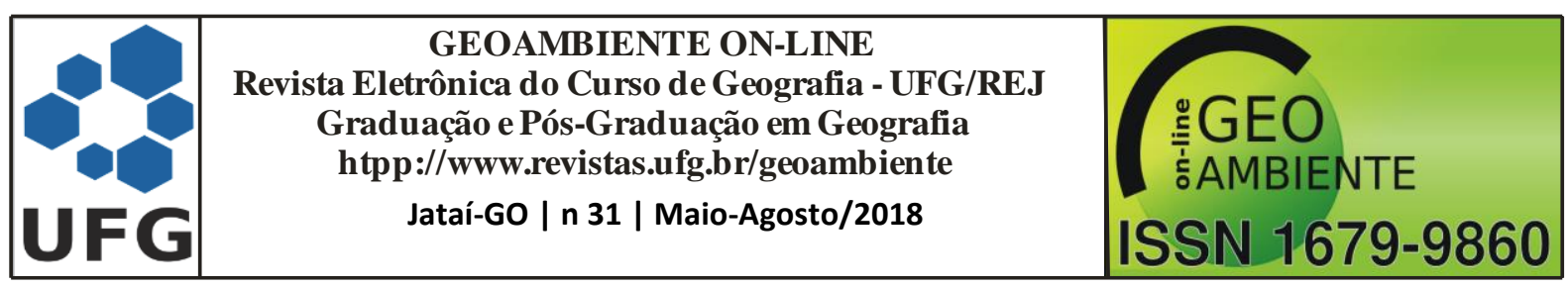

com uma área de $3.186 \mathrm{~m}^{2}$, correspondendo a $0,4 \%$ da área total. Os pontos 10 e 21 não possuem áreas com alta e altíssima suscetibilidade a inundação.

Tabela 1 - Dados quantitativos -pontos de alagamento PMSBMC e das áreas de interesse

\begin{tabular}{|c|c|c|c|}
\hline Pontos PMSBMC & Área m² & $\begin{array}{l}\text { Área de interesse } \\
\mathbf{m}^{2}\end{array}$ & $\begin{array}{c}\mathbf{N}^{0} \text { de residências } \\
\text { na } \\
\text { área de interesse }\end{array}$ \\
\hline 1 & 329.329 & 4.873 & 12 \\
\hline 2 & 24.184 & 3.186 & 7 \\
\hline 3 & 85.211 & 15.739 & 33 \\
\hline 4 & 145.998 & 5.026 & 5 \\
\hline 5 & 275.076 & 71.768 & 68 \\
\hline 6 & 70.222 & 4.435 & 0 \\
\hline 7 & 61.021 & 21.169 & 0 \\
\hline 8 & 235.169 & 13.190 & 17 \\
\hline 9 & 280.895 & 86.788 & 35 \\
\hline 10 & 105.737 & 0 & 0 \\
\hline 11 & 63.481 & 29.314 & 62 \\
\hline 12 & 164.551 & 32.862 & 48 \\
\hline 13 & 112.104 & 23.812 & 17 \\
\hline 14 & 131.331 & 64.089 & 28 \\
\hline 15 & 86.846 & 19.501 & 1 \\
\hline 16 & 583.210 & 85.877 & 63 \\
\hline 17 & 146.516 & 26.062 & 45 \\
\hline 18 & 328.459 & 89.569 & 66 \\
\hline 19 & 179.723 & 24.741 & 36 \\
\hline 20 & 379.934 & 11.939 & 8 \\
\hline 21 & 65.126 & 0 & 0 \\
\hline 22 & 206.601 & 31.884 & 51 \\
\hline 23 & 49.756 & 9.817 & 31 \\
\hline 24 & 83.695 & 4.233 & 0 \\
\hline Total & 4.194.176 & 679.874 & 633 \\
\hline
\end{tabular}

Org.: FERREIRA, M. F. F., 2016.

A área de interesse que possui maior número de residências está área5,em queforam encontradas 68 domicílios, correspondendo a 10,7\% do total. A área que possui o menor número está na área 15 com somente uma residência, o que corresponde a $0,15 \%$ do total. No entanto, a maior densidade residencial foi encontrada na área 23 e a menor densidade residencial foi encontrada na área 15. Nas áreas 6, 7, 10, 21 e 24 não possuem residências nas 


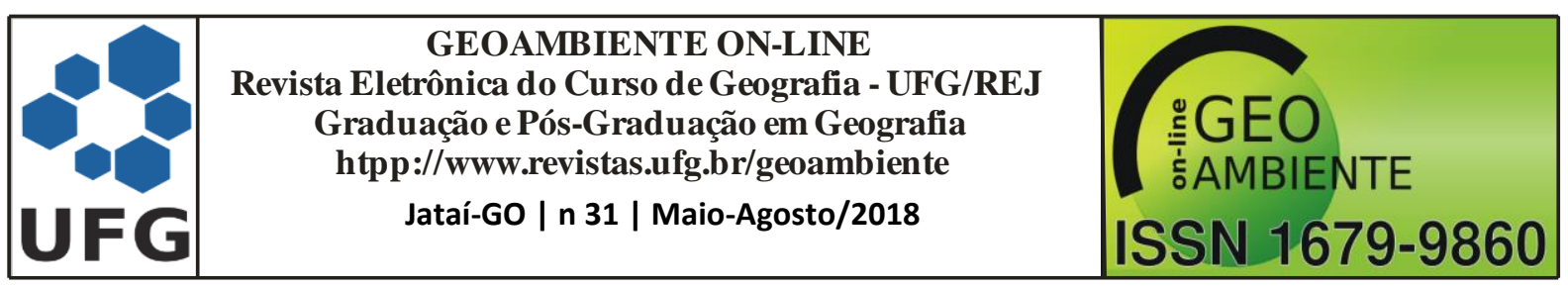

áreas de interesse. A figura 4 representa a espacialização das residências em cada área de interesse da pesquisa.

Figura 4 - Espacialização das residências susceptíveis ao alagamento

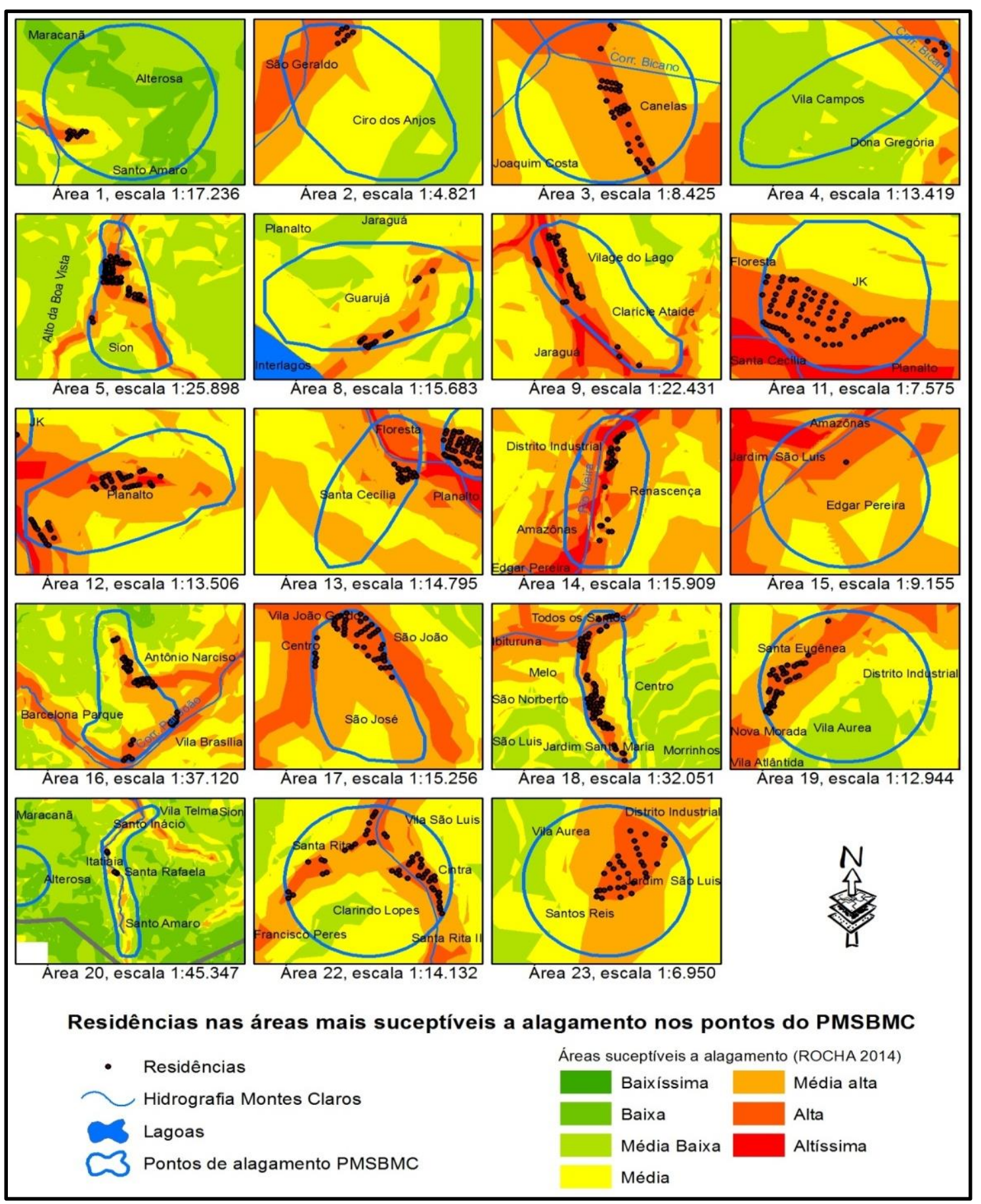

Org.: FERREIRA, M. F. F., 2016. 


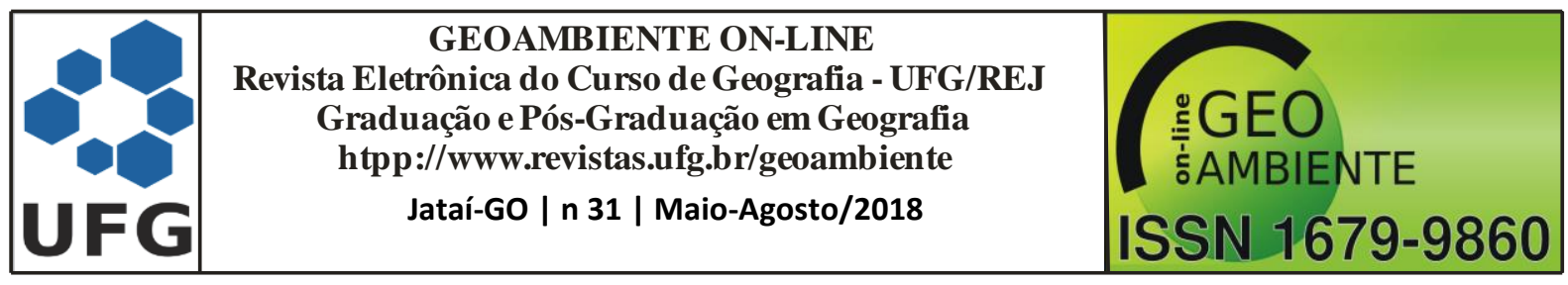

Conforme explicado na metodologia, as áreas de interesse da pesquisa (alta e altíssima suscetibilidade a inundação) foram sobrepostas aos setores censitários do IBGE 2010 e assim foi possível saber as áreas em $\mathrm{m}^{2}$ correspondentes a renda domiciliar e número de moradores.

A figura 5 mostra os setores censitários do IBGE 2010 fragmentado por classes de renda: $(\mathrm{R} \$ 0$ a $\mathrm{R} \$ 347.303,00)$ - $(\mathrm{R} \$ 347.303,01$ a $\mathrm{R} \$ 599.110,00)$ - $(\mathrm{R} \$ 599.110,01$ a $\mathrm{R} \$$ $1.085 .910,00)-(\mathrm{R} \$ 1.085 .910,01$ a $\mathrm{R} \$ 2.078 .143,00)$ - $(\mathrm{R} \$ 2.078 .143,01$ a $\mathrm{R} \$ 3.992 .279,00)$. O valor da renda domiciliar é o total da renda de todos os domicílios do setor e esse número está entre os valores mostrados em cada classe no mapa.

Portanto, na tabela 2, são mostradas as áreas $\mathrm{em}^{2}$ da área de interesse que estão localizadas em cada classe de renda dos setores censitários. Nota-se os seguintes dados: a área de interesse que possui maior extensão em $\mathrm{m}^{2}$ dentro da classe ( $\mathrm{R} \$ 0$ a $\left.\mathrm{R} \$ 347.303,00\right)$ de renda domiciliar é a área 9, com $54.701 \mathrm{~m}^{2}$, correspondendo a 34,4\% da área total. A que possui menor extensão é a área 2 com $2.010 \mathrm{~m}^{2}$ e corresponde a 1,2 \% da área total dessa classe. Somente as áreas 1, 2, 3, 5, 9, 13, 19, 20, 23 e 24 possuem terras nesta classe.

Dentro da classe $(\mathrm{R} \$ 347.303,01$ a $\mathrm{R} \$ 599.110,00)$ a área 14 é a que possui maior extensão, com $35.388 \mathrm{~m}^{2}$, correspondendo a $18,4 \%$ da área total.A que possui menor extensão é a área $3 \mathrm{com}$ somente $58 \mathrm{~m}^{2}$, o que corresponde a $0,03 \%$ do total da classe. Somente as áreas $2,3,5,6,7,8,11,12,13,14,15,17,19,20$, e 22 possuem terras nesta classe.

Na classe (R\$ 599.110,01 a R\$ 1.085.910,00) a área 16 possui a maior extensão, com $85.877 \mathrm{~m}^{2}$, correspondendo a 34.1\%.A área 19 possui a menor extensão, $896 \mathrm{~m}^{2}$, o que corresponde a $0,35 \%$ do total da classe. Somente as áreas 3, 4, 6, 9, 11, 12, 14, 15, 16, 18, 19 e 22 possuem terras nesta classe.

Na classe ( $\mathrm{R} \$ 1.085 .910,01$ a $\mathrm{R} \$ 2.078 .143,00)$ a área 18 possui maior extensão, com $47.175 \mathrm{~m}^{2}$, correspondendo a 93,2 \% do total.A área 15 possui a menor extensão, com 1.467 $\mathrm{m}^{2}$ do total da classe. Somente as áreas $15,17,18$ possuem terras nesta classe.

Por fim, na classe de renda ( $\mathrm{R} \$ 2.078 .143,01$ a $\mathrm{R} \$ 3.992 .279,00)$ somente a área 18 possui terras com $27.220 \mathrm{~m}^{2}$ de extensão. Observa-se, também, que a classe de renda entre $\mathrm{R} \$ 599.110,01$ a $\mathrm{R} \$ 1.085 .910,00$ é a que possui a maior quantidade de área em relação ao total das áreas de interesse, somando $251.260 \mathrm{~m}^{2}, 36,9 \%$.A maior classe de renda $(\mathrm{R} \$$ 2.078.143,01 a $\mathrm{R} \$ 3.992 .279,00)$ é a que possui menor quantidade de área, somente 27.220 $\mathrm{m}^{2}, 4 \%$ da área total de interesse. 


\begin{tabular}{|c|c|c|}
\hline & $\begin{array}{c}\text { GEOAMBIENTE ON-LINE } \\
\text { Revista Eletrônica do Curso de Geografia - UFG/REJ } \\
\text { Graduação e Pós-Graduação em Geografia } \\
\text { htpp://www.revistas.ufg.br/geoambiente } \\
\text { Jataí-Go | n } 31 \text { | Maio-Agosto/2018 }\end{array}$ & $\begin{array}{c}\text { :GEO } \\
\text { ISAMBIENTE } \\
\text { ISSN 1679-9860 }\end{array}$ \\
\hline
\end{tabular}

Figura 5 - Áreas de interesse sobrepostas aos setores censitários (renda domiciliar).

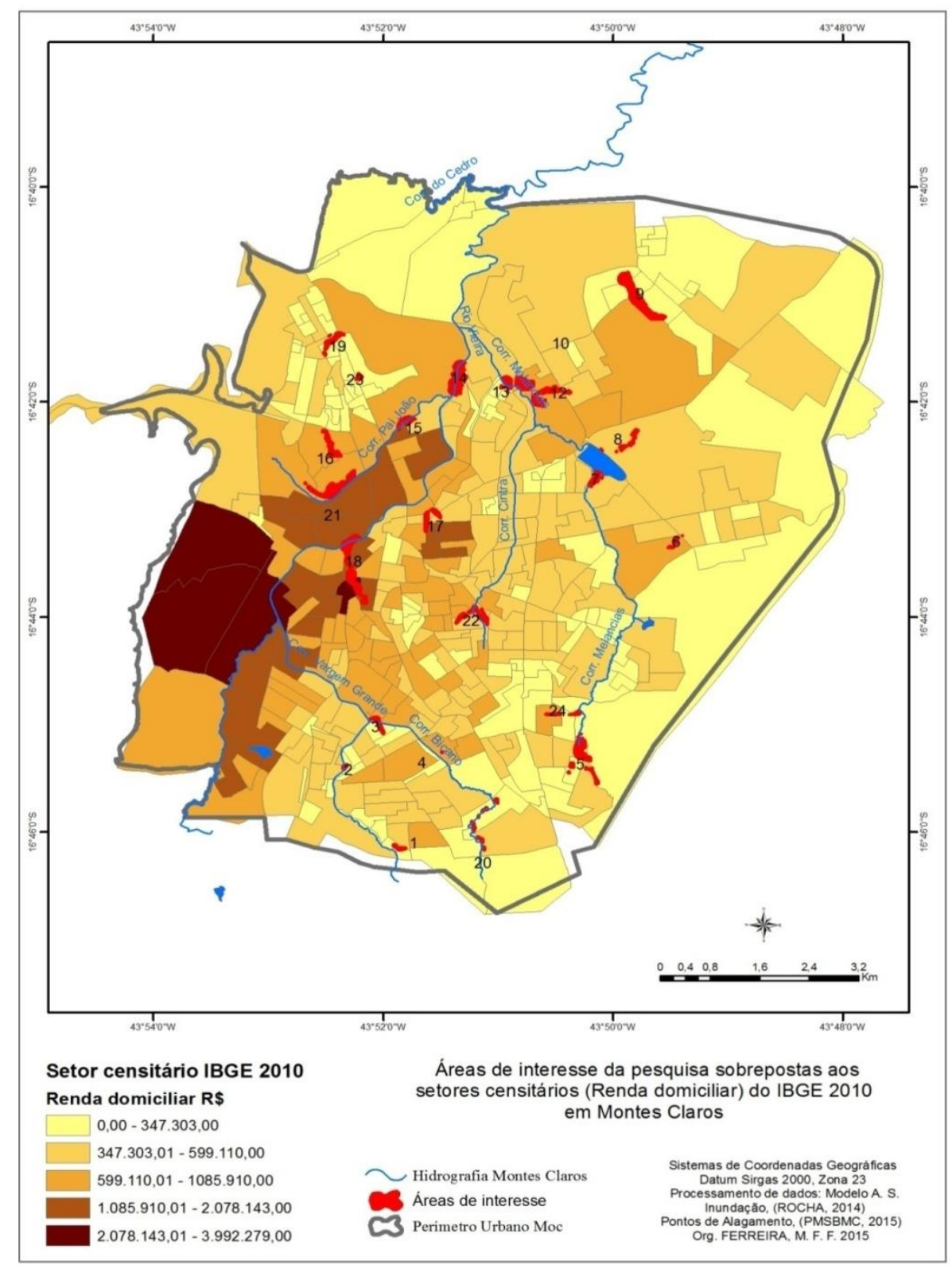

Fonte: IBGE, 2010; PMSBMC, 2014; ROCHA, 2014. Secretária de planejamento Urbano (SEPLAN) - Montes Claros/MG. Org. FERREIRA, M. F. F. (2015). 


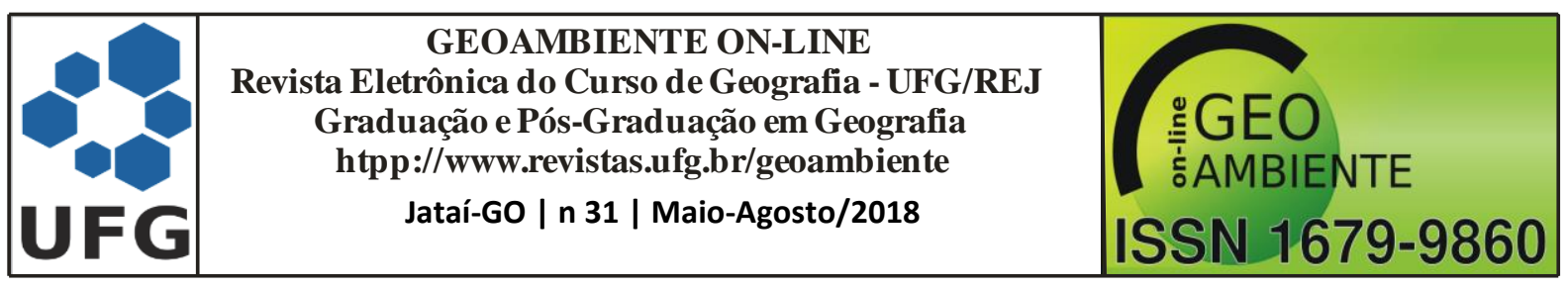

Tabela 2 -Dados quantitativos das áreas de interesse em relação ao setor censitário (renda domiciliar) IBGE 2010

\begin{tabular}{|c|c|c|c|c|c|}
\hline & $\begin{array}{c}\text { Classe de } \\
\text { renda }(\mathrm{R} \$ 0 \text { - } \\
347.303,00)\end{array}$ & $\begin{array}{c}\text { Classe de } \\
\text { renda }(\mathrm{R} \$ \\
347.303,01- \\
599.110,00)\end{array}$ & $\begin{array}{c}\text { Classe de } \\
\text { renda }(\mathrm{R} \$ \\
599.110,01- \\
1.085 .910,00)\end{array}$ & $\begin{array}{c}\text { Classe de } \\
\text { renda }(\mathrm{R} \$ \\
1.085 .910,01 \\
- \\
2.078 .143,00)\end{array}$ & $\begin{array}{c}\text { Classe de } \\
\text { renda } \\
(\mathrm{R} \$ \\
2.078 .143,01- \\
3.992 .279,00)\end{array}$ \\
\hline Área 1 & $4.873 \mathrm{~m}^{2}$ & & & & \\
\hline Área 2 & $2.010 \mathrm{~m}^{2}$ & $1.177 \mathrm{~m}^{2}$ & & & \\
\hline Área 3 & $7.890 \mathrm{~m}^{2}$ & $58 \mathrm{~m}^{2}$ & $7.791 \mathrm{~m}^{2}$ & & \\
\hline Área 4 & & & $5.026 \mathrm{~m}^{2}$ & & \\
\hline Área 5 & $38.273 \mathrm{~m}^{2}$ & $33.495 \mathrm{~m}^{2}$ & & & \\
\hline Área 6 & & $196 \mathrm{~m}^{2}$ & $4.240 \mathrm{~m}^{2}$ & & \\
\hline Área 7 & & $21.169 \mathrm{~m}^{2}$ & & & \\
\hline Área 8 & & $13.190 \mathrm{~m}^{2}$ & & & \\
\hline Área 9 & $54.701 \mathrm{~m}^{2}$ & & $32.087 \mathrm{~m}^{2}$ & & \\
\hline \multicolumn{6}{|l|}{ Área 10} \\
\hline Área 11 & & $4.509 \mathrm{~m}^{2}$ & $24.804 \mathrm{~m}^{2}$ & & \\
\hline Área 12 & & $1.567 \mathrm{~m}^{2}$ & $31.295 \mathrm{~m}^{2}$ & & \\
\hline Área 13 & $6.660 \mathrm{~m}^{2}$ & $17.152 \mathrm{~m}^{2}$ & & & \\
\hline Área 14 & & $35.388 \mathrm{~m}^{2}$ & $28.701 \mathrm{~m}^{2}$ & & \\
\hline Área15 & & $10.622 \mathrm{~m}^{2}$ & $7.413 \mathrm{~m}^{2}$ & $1.467 \mathrm{~m}^{2}$ & \\
\hline Área 16 & & & $85.877 \mathrm{~m}^{2}$ & & \\
\hline Área 17 & & $24.132 \mathrm{~m}^{2}$ & & $1.930 \mathrm{~m}^{2}$ & \\
\hline Área 18 & & & $15.174 \mathrm{~m}^{2}$ & $47.175 \mathrm{~m}^{2}$ & $27.220 \mathrm{~m}^{2}$ \\
\hline Área 19 & $19.272 \mathrm{~m}^{2}$ & $4.573 \mathrm{~m}^{2}$ & $896 \mathrm{~m}^{2}$ & & \\
\hline Área 20 & $11.211 \mathrm{~m}^{2}$ & $727 \mathrm{~m}^{2}$ & & & \\
\hline \multicolumn{6}{|l|}{ Área 21} \\
\hline Área 22 & & $23.928 \mathrm{~m}^{2}$ & $7.956 \mathrm{~m}^{2}$ & & \\
\hline Área 23 & $9.817 \mathrm{~m}^{2}$ & & & & \\
\hline Área 24 & $4.233 \mathrm{~m}^{2}$ & & & & \\
\hline Total & $158.940 \mathrm{~m}^{2}$ & $191.883 \mathrm{~m}^{2}$ & $251.260 \mathrm{~m}^{2}$ & $50.572 \mathrm{~m}^{2}$ & $27.220 \mathrm{~m}^{2}$ \\
\hline
\end{tabular}

Org. FERREIRA, M. F. F., 2016

Estes dados constituem-se em importantes indicadores para conhecer os possíveis impactos que as inundações podem trazer para cada área com alta e altíssima susceptibilidade a inundação. A grande área construída com residências e arruamentos impermeáveis localizadas nas áreas de várzeas, potencializam, ainda mais, o risco de grandes inundações que em muitos casos afetam uma população de baixa renda. Conforme diz no Plano Municipal de Saneamento Básico de Montes Claros somente em 2012 foram desalojadas trezentas e quarenta e cinco famílias em decorrência de inundações em Montes Claros. 


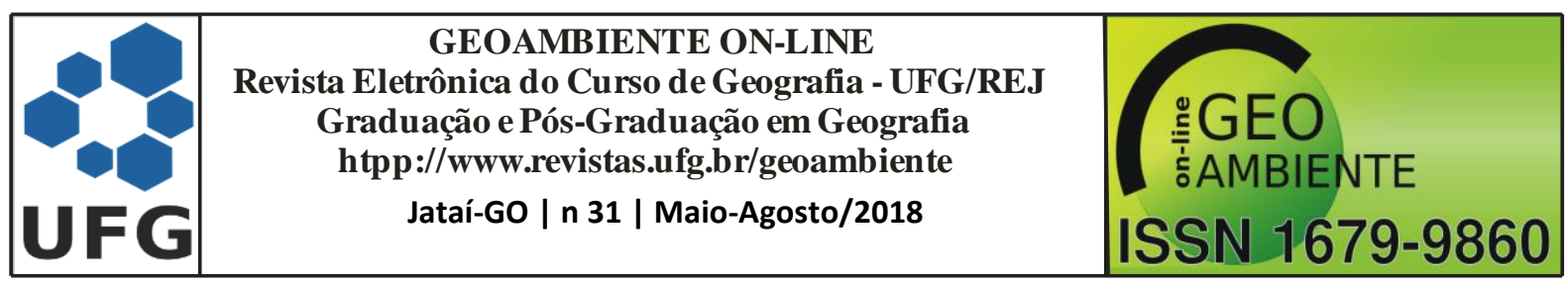

O grande número de residências nas áreas suscetíveis a inundação, mostrado na figura 4 e tabela 1 , evidencia algo comum na grande maioria das cidades brasileiras, já que, na quase totalidade das cidades, não existe nenhuma restrição por parte do Plano Diretor Urbano quanto ao loteamento de áreas de risco de inundação. Além disso, exemplifica outros problemas da área urbana ribeirinha, como as invasões das áreas públicas, pela população de baixa renda. Essas ações inadequadas de ocupação do espaço urbano impactam diretamente a população envolvida.

Normalmente, as áreas mais susceptíveis à inundações são ocupadas pela população de baixa renda, devido à desvalorização comercial ou por serem áreas públicas invadidas. Em Montes Claros, o que se observa não é o comum. A maioria das áreas mais suscetíveis à inundação, que foram analisadas, estão dentro da classe de renda intermediária, ou seja, a maior área com risco de ser atingida pelas inundações não possui população de baixa renda. Até mesmo áreas dentro da classe de renda alta são atingidas pelas inundações em Montes Claros.

Os espaços sujeitos a inundações e alagamentos na cidade são as áreas mais baixas, geralmente áreas de várzeas, ou muito próximas a ela e esse fator, aliado a impermeabilização do solo e deficiência na rede de drenagem, potencializa o risco de alagamentos nos períodos chuvosos.

Observa-se, ainda, a ocorrência de pontos de alagamentos no interior da cidade decorrentes de vazão insuficiente das galerias de drenagem das águas pluviais existentes, geralmente inerentes a pavimentação de ruas e casas construídas em áreas de escoamento superficial. Assim, o volume de água que se infiltra no solo é menor e o escoamento superficial aumenta, provocando os alagamentos urbanos.Junta-se a este fato o acúmulo de lixo nas bocas de lobo da área central da cidade que impedem o escoamento contínuo da água.

\section{Considerações finais}

A desordenada ocupação do espaço urbano gera diversos problemas que refletem no ambiente natural. As inundações urbanas é um problema que vem afetando de forma geral os territórios, fato semelhante ocorre no espaço urbano de Montes Claros. Os resultados desta pesquisa apontam que a causa das inundações está relacionada aos processos de urbanização e aliado à ineficácia do planejamento urbano. 


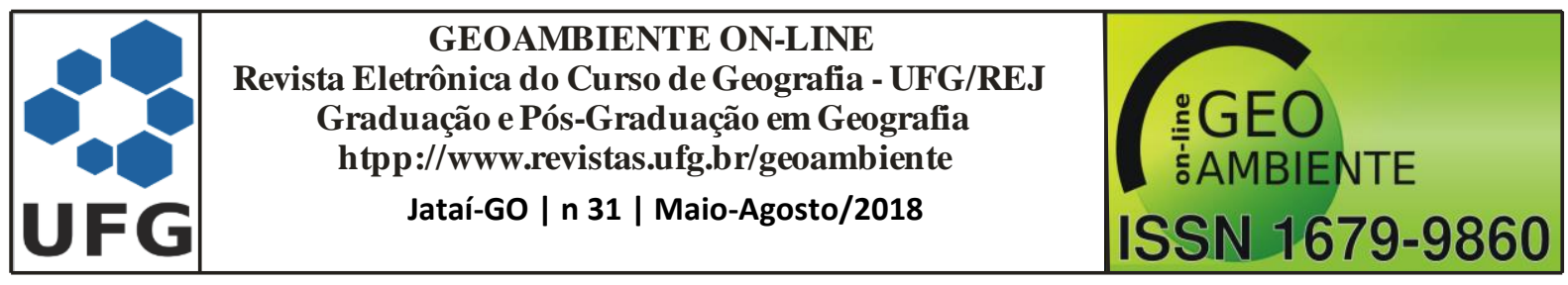

Distinguiu-se neste estudo as áreas e a população atingida pelo fenômeno de inundações. Com base nos resultados obtidos, foram identificadas as áreas com classe de renda da população atingida. Constatou-se a ocupação e loteamentos ribeirinhos, por populações de todas as classes de renda, em áreas sujeitas à inundação periódica, potencializando os riscos de inundações urbanas em áreas de considerável adensamento imobiliário.

Considerando que a dinâmica socioespacial estabelecida no decorrer do processo de desenvolvimento urbano de Montes Claros tem provocado transformações no espaço, faz-se necessário monitorar frequentemente as áreas sujeitas a riscos ambientais na cidade ao longo do tempo e desenvolver pesquisas com os agentes sociais envolvidos.

No tocante ao relatório do PMSBMC (2015), é importante salientar a falta de precisão das áreas apontadas no plano de saneamento que superestima a área e não quantifica as residências vulneráveis.

Foi possível com este trabalho identificar e representar os pontos vulneráveis da sociedade ao risco de inundações na cidade de Montes Claros sem, contudo, envolver toda a complexidade que a temática exige.

\section{Agradecimentos}

Os autores agradecem a FAPEMIG pela bolsa de pesquisa e pela bolsa de mestrado.

\section{Referências}

AMARAL, R.; RIBEIRO, R.R. Enchentes e Inundações. In: Desastres Naturais, conhecer para prevenir.Tominaga, L.K; Santoro, J; Amaral, R. (Organizadores). Instituto Geológico, São Paulo. p. 40-53. 2009.

BUENO, F. Métodos Heurísticos:Teoria e Implementações. Tutorial IFSC/Araranguá, 2009. Disponível em: <https://wiki.ifsc.edu.br/mediawiki/images/b/b7/Tutorial_m\%C3\%A9todos _heur\%C3\%ADsticos.pdf>. Acesso em julho 2016.

BUZAI, G.D.; BAXENDALE, C.A. Análisis Socioespacial con Sistemas de Información Geográfica. Lugar Editorial. Buenos Aires. 2006.

CÂMARA, G.; A. M. V. MONTEIRO; S. DRUCK e M. S. CARVALHO. Análise Espacial e Geoprocessamento. In: Fuks, S. D.; M. S. Carvalho; G. Câmara; A. M. V. Monteiro (eds.), Análise Espacial de Dados Geográficos. Instituto Nacional de Pesquisas Espaciais - Divisão 


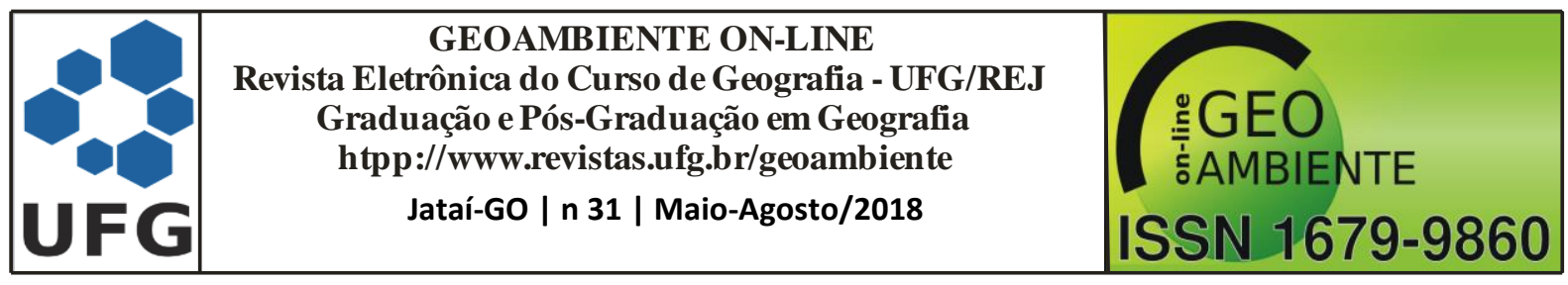

de Processamento de Imagens, São José dos Campos, São Paulo, 2001. Disponível em < http://www.dpi.inpe.br/gilberto/livro/analise/cap1-intro.pdf >. Acesso em: 4 de Janeiro de 2016.

CUNHA, L. Riscos Climáticos no centro de Portugal. Uma leitura geográfica. Revista Geonorte (Manaus) ed. Esp., v.4, n.4, p. 105-115, 2012.

CUNHA, L.;RAMOS, A. M. Riscos Naturais em Portugal: Alguns problemas, perspectivas e tendências no estudo dos Riscos Geomorfológicos. In. FREITAS, M. I. C; LOMBARDO, M. A. (Org.) Riscos e vulnerabilidades: Teoria e prática no contexto Luso-Brasileiro. Edição: $1^{\text {a }}$ São Paulo: Cultura Acadêmica, 2013. (Recurso digital). 19-44.

FRANÇA, I. S. de.; SOARES, B. R. O espaço intra-urbano de uma cidade média e suas centralidades: uma análise de Montes Claros no norte de Minas Gerais. In. Caminhos de Geografia. Uberlândia v. 8, n. 24 DEZ/2007 p. 75 - 94.

GARCIA, R. Metodologias de avaliação da perigosidade e risco associado a movimentos de vertente: aplicação na bacia do Rio Alenquer, Lisboa, 2012. 430p. Dissertação (doutorado). Universidade de Lisboa.

GOERL, R.F.; KOBIYAMA, M. Considerações sobre as inundações no Brasil. In: SIMPÓSIO BRASILEIRO DE RECURSOS HÍDRICOS, 2005, João Pessoa.Anais... 2005. Porto Alegre: ABRH. 10p. Disponível em: Acesso em: 12 abr. 2012.

IBGE. Cidades.2010. Disponível em: <http://cidades.ibge.gov.br/xtras/perfil.php?lang=\&cod mun=3143302> Acesso em: 13/01/2016.

LEITE, M.E.; ROCHA, A.M. Mapeamento da susceptibilidade à inundação em áreas urbanas: o caso da cidade de Montes Claros-MG. Revista Geosul, Florianópolis, v. 31, n. 62, p $125-$ 150, jul./ago. 2016.

LEITE, M. E.; SANTOS, I. S.; ALMEIDA, J. W. L. Mudança de Uso do Solo na Bacia do Rio Vieira, em Montes Claros/MG. Revista Brasileira de Geografia Física. (2011) 779-792. NASCIMENTO, D. J. F. Análise dos desastres noticiados na mídia por meio do jornal impresso de Guarapuava-PR. Guarapuava-PR. 132 f. Dissertação (Mestrado em Geografia) Universidade Estadual do Centro-Oeste, Guarapuava, 2013.

PMSBMC. Plano Municipal de Saneamento Básico referente à prestação dos serviços de abastecimento de água potável, de esgotamento sanitário, de drenagem e manejo das águas pluviais urbanas e de limpeza urbana e manejo de resíduos sólidos de Montes Claros (MG). 


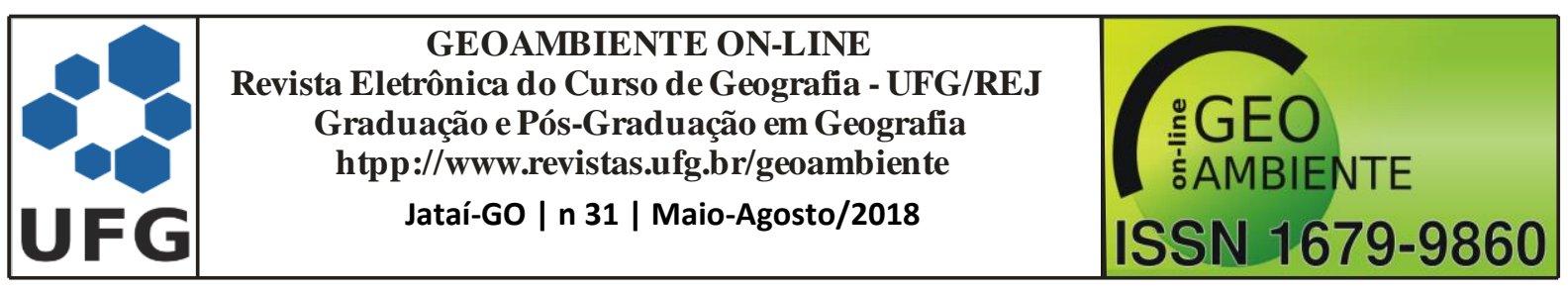

Relatório de Mobilização Social. In. SERENCO - Serviços de Engenharia Consultiva, Março de 2015. Acesso em Dezembro 2015. Disponível em:http://www.montesclaros.mg.gov.br/ agencia_noticias/2015/Plano\%20Saneamento\%20B\%C3\%A1sico/Relat\%C3\%B3rio\%20de\% 20Mobiliza\%C3\%A7\%C3\%A3o\%20Social_0315_R0.pdf.

SILVA, A. M. Bacia do Rio Vieira: caracterização e impactos ambientais. Trabalho de conclusão de curso. Departamento de Geociências, Montes Claros, Unimontes, 2002.

TOLMASQUIM, M. T. Análise socioambiental de alternativas para o atendimento à Interligação Pirapora. Montes Claros, Rio de Janeiro, 2009.

TOMINAGA, L. K; SANTORO, J; AMARAL, R. (Orgs.) Desastres Naturais: conhecer para prevenir. 1.ed $/ 2^{\circ}$ reimpressão. São Paulo: Instituto Geológico, 2011. 196 pp.

TUCCI, C. E. M. Gestão de inundações urbanas. Ministério das cidades. Global WaterPartnership - Wolrd Bank - Unesco, 2005.

TUCCI, C. E. M; BERTONI, J.C. (orgs.).Apostila de Inundações Urbanas da América Latina. Porto Alegre, Associação Brasileira de Recursos Hídricos, 129 p. 2003. 